BMJ Open

Diabetes

Research

\& Care

\title{
Results from NEXT-D: the association of a pre-diabetes-specific health plan and rates of incident diabetes among a national sample of working-age adults
}

Tannaz Moin (D) , ${ }^{1,2}$ Jinnan Li (D) , ${ }^{1}$ Kenrik Duru, ${ }^{1}$ Susan L Ettner, ${ }^{1,3}$ Norman Turk, ${ }^{1}$ Charles Chan, ${ }^{4}$ Abigail M Keckhafer, ${ }^{4}$ Robert H Luchs, ${ }^{4}$ Sam Ho, ${ }^{4}$ Carol M Mangione ${ }^{1,3}$

To cite: Moin T, Li J, Duru K, et al. Results from NEXT-D: the association of a prediabetes-specific health plan and rates of incident diabetes among a national sample of working-age adults. BMJ Open Diab Res Care 2020;8:e001093. doi:10.1136/ bmjdrc-2019-001093

Received 3 December 2019 Revised 20 February 2020 Accepted 21 March 2020

\section{Check for updates}

\section{(C) Author(s) (or their} employer(s)) 2020. Re-use permitted under CC BY-NC. No commercial re-use. See rights and permissions. Published by BMJ.

${ }^{1}$ Department of Medicine, University of California, Los Angeles, California, USA ${ }^{2}$ HSR\&D Center for the Study of Healthcare Innovation, Implementation \& Policy, VA Greater Los Angeles Healthcare System, Los Angeles, California, USA

${ }^{3}$ Fielding School of Public Health, UCLA, Los Angeles, California, USA

${ }^{4}$ United HealthCare Services, Minneapolis, Minnesota, USA

Correspondence to Dr Tannaz Moin; TMoin@mednet.ucla.edu

\section{ABSTRACT}

Background Pre-diabetes affects one-third of adults in the USA and a subset will progress to type 2 diabetes. Our objective was to determine whether a disease-specific health plan, known as the Diabetes Health Plan (DHP), designed to improve care for persons with pre-diabetes and diabetes also led to lower rates of incident diabetes among adults with pre-diabetes.

Methods We examined eligibility and claims data from a large payer who offered the DHP to a national sample of employers. We included adult employees and dependents who were continuously covered by the DHP over a 4-year study window. The primary outcome was incident diabetes. We conducted propensity score matching at the employer level to find comparable control employer groups offering standard plans. Using an adjusted logistic regression model at the individual level, we tested the association between DHP employer group status and incident diabetes diagnosis during the 3 years of postbaseline follow-up.

Findings Our analysis included data from 11965 continuously enrolled adults with pre-diabetes $(n=1538$ from nine employers offering DHP; $n=10427$ from 105 control employers offering standard plans). DHP employees and covered dependents with pre-diabetes had an $8 \%$ lower absolute predicted probability of incident diabetes compared with individuals from employer groups offering standard benefit plans (29\% predicted probability of incident diabetes for DHP vs $37 \%$ for controls, $p<0.001$ ). Conclusions A pre-diabetes-specific health benefit design was associated with lower rates of incident diabetes and represents an area of needed future study.

\section{BACKGROUND}

Pre-diabetes is prevalent and can significantly increase lifetime risk of incident diabetes. ${ }^{1-3}$ In the USA, 84 million adults have pre-diabetes and up to $11 \%$ will progress to diabetes within 3 years. ${ }^{1}$ Large randomized trials have demonstrated that intensive lifestyle change and metformin can lower incident diabetes risk. ${ }^{4}$ Patients who are aware of their pre-diabetes diagnosis are more likely to make healthy lifestyle changes to lower

\section{Significance of this study}

What is already known about this subject?

- Health insurance benefit designs have significant implications for healthcare outcomes and costs.

What are the new findings?

- We found that a pre-diabetes-specific health design was associated with lower rates of incident diabetes among US employees offered the plan as compared with control employees enrolled in standard health plans.

How might these results change the focus of research or clinical practice?

- Novel disease-specific health plans may be a promising strategy to increase uptake of evidence-based care and lower rates of incident diabetes.

their risk of diabetes. ${ }^{5}$ However, most patients with pre-diabetes are not aware of their diagnosis $^{6-8}$ and uptake of evidence-based options to lower incident diabetes risk, such as intensive lifestyle intervention and metformin, remains low.

Innovative health insurance benefit designs that can (1) help increase pre-diabetes awareness and (2) incentivize patients and providers to use evidence-based diabetes prevention options may help address current gaps in pre-diabetes care.

The Diabetes Health Plan (DHP) is the first disease-specific health plan in the USA for patients with diabetes and pre-diabetes (not to be confused with the Diabetes Prevention Program (DPP), which is a 12-month intensive lifestyle change program for adults at risk for diabetes). The DHP uses claims and laboratory data to identify employees who are likely to have pre-diabetes. Eligible employees and dependents are made aware of their pre-diabetes diagnosis as an eligibility 
requirement for DHP enrollment. The DHP also includes additional features such as quarterly scorecards to remind patients of the importance of an annual provider visits and follow-up hemoglobin A1c (HbAlc) testing. ${ }^{9}$ To increase access to evidence-based ambulatory care, the DHP also offers a variety of features such as reduced cost sharing for medications and office visits and free or low-cost resources for self-management support. As such, patients may be more willing and/or able to engage in recommended preventive care.

The fact that only some employer groups offer the DHP represents a unique opportunity to conduct a rigorous evaluation of this real-world, naturally occurring intervention, also known as a natural experiment. ${ }^{10}$ Our objective was to examine rates of incident diabetes over a 3-year time frame among employees and covered dependents with pre-diabetes who are offered the DHP as compared with those offered standard health benefit plans.

\section{METHODS}

We conducted a retrospective, intent-to-treat analysis using 2009-2013 insurance claim and laboratory value data from individuals in employer groups contracting with UnitedHealthcare (UHC) to offer either the DHP or a standard health plan (ie, control). This study was conducted under the oversight of Natural Experiments for Translation in Diabetes (NEXT-D), a multicenter research network funded by the Centers for Disease Control and Prevention (Division of Diabetes Translation) and the National Institute of Diabetes and Digestive and Kidney Diseases (grant number U58DP002722-05). All NEXT-D studies are evaluations of 'naturally' occurring health polices and/or interventions (ie, without randomization), using the strongest observational research designs possible and conducted in close collaboration with organizations implementing those programs. ${ }^{11-13}$ The academic team members analyzed all data independently and retained sole authority over all publication-related decisions throughout the course of the study.

\section{Study population}

We received data for 708 large US employer groups who contracted with UHC between 2009 and 2013. Among these, 563 employer groups had the needed administrative, laboratory, and pharmacy claims data over 4 continuous years to conduct the analyses and $<90 \%$ of their employees in high deductible plans. Nine employer groups offered the DHP and 554 employer groups offered standard benefit plans (ie, control employer groups). We excluded controls located in the midAtlantic region (where no DHP groups were located, $\mathrm{n}=49$ ) and those with $<20$ members with pre-diabetes or diabetes $(n=19)$. Since randomization was not possible, we fit an employer-level propensity model to identify control employer groups most comparable to the nine DHP employer groups. ${ }^{14} 15$ The propensity model included mean employer size, mean employee salary, mean age of employees and covered dependents, proportion of females, race/ethnicity, proportion with at least one chronic condition, proportion with pre-diabetes, proportion in high deductible plans, geographic region, as well as UHC proprietary estimates of average health plan risk score and generosity of benefit. Propensity score modeling yielded 105 control groups most comparable to the nine DHP employer groups (ie, within the region of common support) which we included in our final analytic sample. ${ }^{1617}$

The baseline period was defined as 12 months prior to DHP implementation for DHP employer groups (ie, 2009 or 2010) and 2010 for all control employer groups. We included data from all employees and covered dependents with pre-diabetes at baseline; participants had to be continuously enrolled in a UHC health plan and 18-64 years old during the 4-year study window. Pre-diabetes was defined by any of the following: (1) >2 International Classification of Diseases 9th Revision (ICD-9) diagnoses of 790.2x from an inpatient or outpatient claim; or (2) last $\mathrm{HbAlc}$ value of $5.7 \%-6.4 \%$ or last fasting plasma glucose (FPG) value of $100-125 \mathrm{mg} / \mathrm{dL}$ or last 2-hour oral glucose tolerance test (OGTT) value of $140-199 \mathrm{mg} / \mathrm{dL}$. We excluded patients with a baseline history of diabetes or women with gestational diabetes or pregnancy during the study window. For DHP employer groups, data from all eligible employees and covered dependents with prediabetes were included regardless of DHP enrollment, consistent with an intent-to-treat design.

\section{Primary outcome}

The primary outcome was incident diabetes diagnosis during the 3years of follow-up after the baseline year. Incident diabetes was defined by any of the following: (1) $>1$ ICD-9 diagnosis code of 250.xx from an inpatient or outpatient claim; or (2) an A1c $>6.5 \%$ or a FPG $>125 \mathrm{mg} /$ $\mathrm{dL}$ or a 2-hour OGTT value of $\geq 200 \mathrm{mg} / \mathrm{dL}$; or (3) $>1$ prescription fills for insulin or an antiglycemic medication other than metformin. Patients who met the diabetes diagnostic criteria at any point during the follow-up period were considered to have incident diabetes. There were 327 patients from the DHP groups (21\%) and 4998 patients from the control group (48\%) who did not meet any of the diabetes diagnostic criteria during 3 years of follow-up and did not have diagnostic labs available in year 3 to conclusively determine the primary outcome of interest. In these instances, we used multiple imputation to estimate the probability of incident diabetes during the 3 years of postbaseline follow-up. ${ }^{18}$

\section{Covariates}

The primary predictor of interest was DHP employer group. Individual-level model adjusters included gender, age, race/ethnicity, education, income, baseline lab test count (ie, A1c, FPG, and OGTT), baseline severity of pre-diabetes, obesity, and mental health comorbidity. 
Age and gender were obtained from UHC eligibility files. Education, income, and race/ethnicity were estimated by UHC using a proprietary algorithm that incorporated geographic locators (zip codes), consumer survey information, census income data, and first, middle, and last names. We obtained the average number of baseline A1c/FPG/OGTT labs from claims data and defined the baseline pre-diabetes severity, or degree of dysglycemia, as 'high' if A1c was $6 \%-6.4 \%$ or FPG was $110-125 \mathrm{mg} / \mathrm{dL}$ at baseline or 'low' if baseline A1c was $5.7 \%-5.9 \%$ or FPG was $100-109 \mathrm{mg} / \mathrm{dL}$. When both A1c and FPG results were available, we used Alc as the primary stratification variable for the 'high' versus 'low' severity classification. Comorbidities such as obesity (body mass index $\geq 30 \mathrm{~kg}$ / $\mathrm{m}^{2}$ ) and mental health conditions (schizophrenia, depression, anxiety and post-traumatic stress disorder) were defined as one or more ICD-9-related diagnoses from inpatient or outpatient claims.

Age, obesity, and baseline pre-diabetes severity were included because these are established risk factors for diabetes. ${ }^{9}$ Mental health condition was included since schizophrenia and treatment with some atypical antipsychotics or antidepressants are also risk factors for diabetes. We included race because certain groups (such as African-Americans) have a higher risk for diabetes. Gender was included because women are more likely to use health services overall, which may affect the likelihood of being tested for diabetes (ie, detection bias). The baseline lab test count also served as a proxy for willingness and/or motivation to obtain follow-up care and/ or testing. Lastly, we included estimates of income and education because these are proxies for health literacy and financial resources.

\section{Statistical analysis}

We used a logistic regression model with cluster-adjusted estimates of variance to test the association between DHP employer group status and incident diabetes diagnosis during the 3 years of follow-up after baseline. To address the issue of ambiguous outcome due to lack of follow-up labs, we conducted multiple imputation by chained equations using all the variables in the analytic model while simultaneously addressing missing data for race/ ethnicity $(6 \%)$, education $(2 \%)$, and income $(7 \%) .{ }^{18}$ Multiple imputation was performed in STATA (V.14) using the user-written 'ice' command, and the 'mi estimate' command was then used to estimate the missing variables, including the primary outcome of interest across 10 imputed data sets. ${ }^{190}$ The resulting estimations were combined across the imputed data sets using Rubin rules. ${ }^{19} 20$ The STATA 'margins' command was used to obtain predicted probabilities of incident diabetes diagnosis over the 3-year follow-up window.

\section{RESULTS}

We analyzed data from 11965 continuously enrolled patients with pre-diabetes $(\mathrm{n}=1538$ from 9 employers offering the DHP; n=10427 from 105 control employers offering standard plans). Sixty-eight percent of eligible patients with pre-diabetes $(n=1039)$ were enrolled in the DHP, but all 1538 were included in this intent-to-treat analysis. Compared with controls, employees and covered dependents from DHP employer groups were more likely to be female ( $54 \%$ vs $44 \%$ female, $\mathrm{p}<0.001$ ), were slightly older (mean age 51 years vs 50 years, $\mathrm{p}<0.001$ ), were less educated, had lower income, were more likely to be African-American and less likely to be Asian (table 1). The proportion of individuals with higher levels of baseline dysglycemia (A1c $6.0 \%-6.4 \%$ or FPG $110-125 \mathrm{mg}$ / $\mathrm{dL}$ ), obesity, and mental health diagnosis was similar across DHP and control employer groups.

Among complete cases, the unadjusted rate of incident diabetes diagnosis over the 3-year follow-up was $26 \%$ for individuals from DHP employer groups versus $35.4 \%$ for individuals from control employer groups $(p<0.001)$. After multiple imputation and controlling for covariates, there was still a significant difference in the predicted probability of incident diabetes diagnosis, $29 \%$ for individuals from DHP employer groups versus $37 \%$ in control employer groups $(\mathrm{p}=0.001$, table 2$)$.

Higher age, higher A1c/FPG value at baseline, obesity and 'other' race were also associated with significantly higher predicted probability of incident diabetes. Higher education, income, and having follow-up lab testing at baseline were associated with significantly lower predicted risk of incident diabetes. We also conducted a sensitivity analysis using a more stringent diagnostic criterion of two or more ICD-9 codes to define diabetes. With this approach, the estimated association between DHP availability and the predicted probability of incident diabetes was unchanged from the results after multiple imputation described above (28\% for individuals from DHP employer groups vs $36 \%$ in control employer groups, $\mathrm{p}<0.001)$.

\section{DISCUSSION}

Our analysis showed the risk of progression from prediabetes to diabetes was significantly lower for persons with pre-diabetes in employer groups offering the DHP. Employees and covered dependents from DHP employer groups had an $8 \%$ lower absolute predicted probability of incident diabetes over 3 years of follow-up after baseline compared with those from employer groups offering standard benefit plans. Our finding of an $8 \%$ absolute reduction, translating into a $21 \%$ relative reduction compared with the $37 \%$ incidence rate among the comparison group, can be measured against the effect size observed in the intensive lifestyle arms and metformin arms of the DPP study. In 2002, this randomized controlled study demonstrated that intensive lifestyle intervention reduced incidence of diabetes by $58 \%$ and metformin reduced the incidence by $31 \%$, as compared with placebo over 2.8 years. ${ }^{4}$ In contrast, the DHP is a relatively light touch approach that still manages to have a meaningful 
Table 1 Baseline characteristics of employees and dependents with pre-diabetes

\begin{tabular}{|c|c|c|c|}
\hline Characteristic & $\begin{array}{l}\text { DHP } \\
(n=1538)\end{array}$ & $\begin{array}{l}\text { Control } \\
(n=10427)\end{array}$ & $P$ value \\
\hline Female & $54 \%$ & $44 \%$ & $<0.001$ \\
\hline Age & $51.2(8.7)$ & $49.8(8.8)$ & $<0.001$ \\
\hline Education & & & $<0.001$ \\
\hline HS or less & $38 \%$ & $31 \%$ & \\
\hline Some college & $55 \%$ & $52 \%$ & \\
\hline $\begin{array}{l}\text { Bachelor's degree } \\
\text { or above }\end{array}$ & $7 \%$ & $17 \%$ & \\
\hline Income & & & $<0.001$ \\
\hline$<\$ 30000$ & $6 \%$ & $5 \%$ & \\
\hline$\$ 30000-\$ 49000$ & $24 \%$ & $18 \%$ & \\
\hline$\$ 50000-\$ 74000$ & $29 \%$ & $30 \%$ & \\
\hline$\$ 75000+$ & $41 \%$ & $47 \%$ & \\
\hline Race/ethnicity & & & $<0.001$ \\
\hline White & $72 \%$ & $71 \%$ & \\
\hline Hispanic & $15 \%$ & $16 \%$ & \\
\hline African-American & $10 \%$ & $7 \%$ & \\
\hline Asian & $2 \%$ & $5 \%$ & \\
\hline Other & $<1 \%$ & $<1 \%$ & \\
\hline $\begin{array}{l}\text { A1c/FPG/OGTT lab } \\
\text { tests in baseline } \\
\text { year }(n)\end{array}$ & & & $<0.001$ \\
\hline 0 & $7 \%$ & $14 \%$ & \\
\hline 1 & $60 \%$ & $62 \%$ & \\
\hline 2 & $22 \%$ & $17 \%$ & \\
\hline $3+$ & $11 \%$ & $7 \%$ & \\
\hline $\begin{array}{l}\text { Higher A1c/FPG at } \\
\text { baseline }\end{array}$ & $32 \%$ & $31 \%$ & 0.347 \\
\hline Obese & $8 \%$ & $8 \%$ & 0.287 \\
\hline $\begin{array}{l}\text { Mental health } \\
\text { comorbidity }\end{array}$ & $13 \%$ & $14 \%$ & 0.075 \\
\hline
\end{tabular}

Mental health comorbidity was defined by $\geq 1$ International Classification of Diseases 9th Revision (ICD-9) related diagnosis for schizophrenia, depression, anxiety and/or post-traumatic stress disorder. Higher A1c/FPG at baseline=baseline A1c 6.0\%$6.4 \%$ or FPG $110-125 \mathrm{mg} / \mathrm{dL}$. Obese was defined by $\geq 1$ ICD-9 related diagnosis of body mass index $(\mathrm{BMI}) \geq 30 \mathrm{~kg} / \mathrm{m}^{2}$.

Bold values denote statistical significance at the $p<0.05$ level DHP, Diabetes Health Plan; FPG, fasting plasma glucose; HS, high school; OGTT, oral glucose tolerance test.

effect size. More importantly, DHP-like insurance benefit designs are implementable on a national scale since $60 \%$ of US adults are currently insured through employersponsored insurance programs. ${ }^{21}$

The mechanism by which a disease-specific health insurance benefit design, such as the DHP, may help prevent or delay development of diabetes is likely twofold. First, since pre-diabetes is an explicit DHP eligibility criterion, our findings may result in part from the increased awareness of a pre-diabetes diagnosis afforded by the DHP. Patients who otherwise might not be aware of their diagnosis know they are being offered the DHP based on their pre-diabetes diagnosis and studies have shown that pre-diabetes awareness can activate patients to engage in health promotion activities. ${ }^{58}$ The DHP also incorporates features to increase compliance with recommended preventive care, such as quarterly scorecards that are mailed to patients reminding them of recommended care (eg, annual visit with their primary care provider). Since education alone may not be enough to lead to behavior change, the DHP also enhances access to evidence-based pre-diabetes care, possibly making it easier for patients to engage in the recommended care. This includes free or reduced cost sharing for follow-up HbAlc testing, as well as access to in-person or online lifestyle intervention programs and/or metformin, which are the mainstay of pre-diabetes treatment and diabetes risk reduction. ${ }^{9}$

The proposed patient activation by the DHP is nicely demonstrated by the differential rates of follow-up glucose lab testing between DHP and control employers. We identified at least one A1c/FPG/OGTT follow-up test for $89 \%$ of individuals from DHP groups compared with only $66 \%$ from standard benefits/controls in any of the three postbaseline years $(p<0.001)$. Thus, our data show that participants from DHP groups were much more likely to have recommended follow-up glucose testing in accordance with most national care recommendations for repeat annual diabetes screening for those with prediabetes. ${ }^{9}$ Although this increased testing creates a potential detection bias towards 'higher' rates of progression (ie, increased rates of testing may increase the chance of diagnosing incident diabetes), our unadjusted results showed lower rates of incident diabetes among employees and dependents covered by the DHP. It is likely that rates of incident diabetes among the control population were even higher than reported but went undiagnosed as these patients were never tested during the follow-up period. We used multiple imputation to address this differential in the availability of the primary outcome, and our results lean towards more conservative estimates of the difference between the two comparison groups. Our intent-to-treat design, which included all DHP employees and dependents with pre-diabetes whether or not they enrolled in the DHP, also leans towards more conservative estimates.

Overall, our findings should be of broad interest since $37 \%$ of US adults are currently estimated to have prediabetes. ${ }^{1}$ To our knowledge, this is also one of the first studies to examine the impact of a disease-specific health insurance benefit design on outcomes for patients with pre-diabetes. Our findings indicate that health insurance benefit designs that help increase pre-diabetes awareness by devoting resources to identify and inform patients of their pre-diabetes diagnosis, incorporating features to increase adherence with recommended care, and providing incentives and/or reduce barriers to recommended care may be a viable means of preventing or 
Table 2 The adjusted predicted probability of incident diabetes

\begin{tabular}{|c|c|c|c|c|c|}
\hline Baseline characteristic & & $\begin{array}{l}\text { Predicted } \\
\text { probability }\end{array}$ & $\begin{array}{l}\text { Absolute } \\
\text { change from } \\
\text { reference }\end{array}$ & $\begin{array}{l}\text { Relative change } \\
\text { from reference }\end{array}$ & $P$ value \\
\hline \multirow[t]{2}{*}{ DHP status } & Non-DHP & 0.37 & & & \\
\hline & DHP & 0.29 & -0.08 & -0.21 & 0.001 \\
\hline \multirow[t]{2}{*}{ Gender } & Female & 0.37 & & & \\
\hline & Male & 0.35 & -0.02 & -0.04 & 0.092 \\
\hline \multirow[t]{4}{*}{ Age } & $19-34$ & 0.30 & & & \\
\hline & $35-44$ & 0.33 & 0.03 & 0.13 & 0.325 \\
\hline & $45-54$ & 0.37 & 0.07 & 0.22 & 0.018 \\
\hline & $55-62$ & 0.38 & 0.08 & 0.25 & 0.002 \\
\hline \multirow[t]{3}{*}{$\begin{array}{l}\text { Baseline risk based on } \\
\text { level of dysglycemia }\end{array}$} & $\begin{array}{l}\text { Low } \\
\text { A1c } 5.7 \%-5.9 \% \\
\text { FPG } 100- \\
109 \mathrm{mg} / \mathrm{dL}\end{array}$ & 0.29 & & & \\
\hline & $\begin{array}{l}\text { High } \\
\text { A1c 6\%-6.4\% } \\
\text { FPG 110- } \\
125 \mathrm{mg} / \mathrm{dL}\end{array}$ & 0.50 & 0.21 & 0.74 & $<0.001$ \\
\hline & ICD-9/OGTT & 0.34 & 0.05 & 0.16 & 0.454 \\
\hline \multirow{4}{*}{$\begin{array}{l}\text { Baseline A1c/FPG/OGTT } \\
\text { lab test count }\end{array}$} & 0 & 0.71 & & & \\
\hline & 1 & 0.30 & -0.41 & -0.57 & $<0.001$ \\
\hline & 2 & 0.28 & -0.43 & -0.60 & $<0.001$ \\
\hline & $3+$ & 0.32 & -0.39 & -0.55 & $<0.001$ \\
\hline \multirow[t]{2}{*}{ ICD-9 obesity } & No & 0.35 & & & Yes \\
\hline & 0.47 & 0.12 & 0.36 & $<0.001$ & Education \\
\hline HS or less & 0.38 & & & & \\
\hline Some college & 0.35 & -0.03 & -0.07 & 0.117 & \\
\hline College degree & 0.33 & -0.05 & -0.14 & 0.019 & Income \\
\hline$<\$ 30000$ & 0.41 & & & & \\
\hline$\$ 30000-\$ 49000$ & 0.38 & -0.03 & -0.06 & 0.325 & \\
\hline$\$ 50000-\$ 74000$ & 0.35 & -0.05 & -0.13 & 0.032 & \\
\hline$\$ 75000+$ & 0.34 & -0.06 & -0.15 & 0.016 & Race/ethnicity \\
\hline White & 0.35 & & & & \\
\hline Hispanic & 0.37 & 0.02 & 0.05 & 0.127 & \\
\hline African-American & 0.35 & -0.01 & -0.02 & 0.649 & \\
\hline Asian & 0.38 & 0.02 & 0.06 & 0.388 & \\
\hline Other & 0.51 & 0.16 & 0.44 & 0.031 & Mental health comorbidity \\
\hline No & 0.36 & & & & \\
\hline
\end{tabular}

Continued 
Table 2 Continued

\begin{tabular}{|c|c|c|c|c|c|}
\hline Baseline characteristic & & $\begin{array}{l}\text { Predicted } \\
\text { probability }\end{array}$ & $\begin{array}{l}\text { Absolute } \\
\text { change from } \\
\text { reference }\end{array}$ & $\begin{array}{l}\text { Relative change } \\
\text { from reference }\end{array}$ & $P$ value \\
\hline Yes & 0.37 & 0.02 & 0.05 & 0.293 & $\begin{array}{l}\text { Mental health comorbidity } \\
\text { was defined by } \geq 1 \text { ICD- } \\
9 \text { related diagnosis } \\
\text { for schizophrenia, } \\
\text { depression, anxiety and/ } \\
\text { or post-traumatic stress } \\
\text { disorder. Higher A1c/ } \\
\text { FPG at baseline=baseline } \\
\text { A1c } 6.0 \%-6.4 \% \text { or FPG } \\
110-125 \mathrm{mg} / \mathrm{dL} \text {. Obese was } \\
\text { defined by } \geq 1 \text { ICD-9 related } \\
\text { diagnosis of body mass } \\
\text { index (BMI) } \geq 30 \text { kg/m }{ }^{2} \text {. } \\
\text { Bold values denote } \\
\text { statistical significance at the } \\
\text { p }<0.05 \text { level } \\
\text { DHP, Diabetes Health } \\
\text { Plan; FPG, fasting plasma } \\
\text { glucose; HS, high school; } \\
\text { ICD-9, International } \\
\text { Classification of Diseases } \\
\text { 9th Revision; OGTT, oral } \\
\text { glucose tolerance test. }\end{array}$ \\
\hline
\end{tabular}

delaying incident diabetes for working-age adults with pre-diabetes. The DHP places strong emphasis on the importance of prevention and regular use of primary care services, highlighting the importance of aligning incentives and payment structures for effective delivery of preventive care services for persons with pre-diabetes. Our findings may help inform future benefit design and/ or national policies surrounding pre-diabetes care. In many ways, the DHP is a test case of a concept of diseasespecific benefit design that deserves further study. This concept is akin to personalized medicine at the benefit level and can also be tested in other costly chronic conditions where there are well-established ambulatory treatment guidelines.

There are also several limitations to consider. First, because this was a claims-based analysis, possible misclassification of pre-diabetes and diabetes may have occurred. However, we conducted a sensitivity analysis that used a stricter definition of $\geq 2$ ICD codes for our primary outcome of diabetes which did not impact our results. Second, some employer groups may have implemented complementary wellness initiatives which our claims-based analysis would not capture. However, we used propensity score matching at the employer level to find comparable control employer groups offering standard plans. Third, our analysis focused on commercially insured adults and may not be generalizable to uninsured or older patients. However, our focus on working-age adults is important because pre-diabetes affects more than one in three adults older than 20 years and the lifetime risk of incident diabetes is highest for younger individuals with pre-diabetes. Finally, our data were limited to 3 years of follow-up. However, our effect size of $8 \%$ absolute risk reduction over just 3 years seems clinically meaningful, particularly when considered across a population level.

In summary, the health and well-being of large segments of the US population and their associated healthcare costs are at stake if diabetes prevention is not prioritized. The sheer number of individuals affected with prediabetes necessitates the use of multifaceted approaches to curb this epidemic. Health insurance benefit designs that increase pre-diabetes awareness and enhance access to evidence-based care are associated with lower rates of incident diabetes and represent an important area of future study.

Acknowledgements The authors thank Ms Anya Kirvan and Ms Karen M Mulready for their assistance in acquiring the UHC data necessary to conduct this study, Dr Romain Neugebauer for his helpful guidance on the statistical methods, as well as Ms Carolina Vasquez and Ms Lindsay Kimbro for their administrative and project management support. Lastly, the oversight of the Natural Experiments for Translation in Diabetes (NEXT-D) research network was invaluable.

Contributors All authors (1) made substantial contributions to conception and design, acquisition of data, or analysis and interpretation of data, (2) drafted the article or revised it critically for important intellectual content, (3) gave final approval of the version to be published, and (4) agreed to be accountable for all aspects of the work in ensuring that questions related to the accuracy or integrity of any part of the work are appropriately investigated and resolved. Study concept and design: CMM, KD, SLE, TM, AMK, RHL, SH. Acquisition of data: RHL, AMK, CC, SH. Analysis and interpretation of data: CMM, KD, SLE, TM, JL, NT. Drafting of the manuscript: TM. Critical revision of the manuscript for important intellectual content: CMM, KD, NT, SLE. Statistical analysis: SLE, JL, NT. Obtained funding: CMM, KD. Administrative, technical, or material support: CMM, KD, CC, RHL, AMK, SH. Study supervision: CMM, KD. TM and CMM had full access to all of the data in 
the study and take responsibility for the integrity of the data and the accuracy of the data analysis.

Funding This study was jointly funded by the Centers for Disease Control and Prevention (Division of Diabetes Translation) and the National Institute of Diabetes and Digestive and Kidney Diseases as part of the Natural Experiments for Translation in Diabetes (NEXT-D) study (grant number DP002722). TM also receives support from Department of Veterans Affairs (QUE15-272, QUE15286, and CSP2002). CMM receives support from the University of California at Los Angeles, Resource Centers for Minority Aging Research Center for Health Improvement of Minority Elderly under National Institutes of Health (NIH)/NIA Grant P30-AG021684, and from NIH/National Center for Advancing Translational Sciences UCLA Clinical and Translational Science Institute Grant UL1TR001881. CMM holds the Barbara A. Levey and Gerald S. Levey Endowed Chair in Medicine, which partially supported her work. KD's effort is also supported in part by the University of California, Los Angeles, Resource Center for Minority Aging Research, Center for Health Improvement of Minority Elderly (RCMAR/CHIME) under NIH/NIA Grant P30-AG021684.

Disclaimer The findings and conclusions in this manuscript are those of the authors and do not necessarily represent the views of the Centers for Disease Control and Prevention (CDC) or the National Institutes of Health (NIH). CMM is a vice chairperson of the U.S. Preventive Services Task Force. This article does not represent the views and policies of the U.S. Preventive Services Task Force.

Competing interests CC, RHL, SH, and AMK are former employees of UnitedHealthcare.

Patient consent for publication Not required.

Ethics approval The study was approved by the Institutional Review Board at the University of California, Los Angeles.

Provenance and peer review Not commissioned; externally peer reviewed.

Data availability statement All data are proprietary and owned by UnitedHealthcare. Per our Data Use Agreement, we are not permitted to share any data.

Open access This is an open access article distributed in accordance with the Creative Commons Attribution Non Commercial (CC BY-NC 4.0) license, which permits others to distribute, remix, adapt, build upon this work non-commercially, and license their derivative works on different terms, provided the original work is properly cited, appropriate credit is given, any changes made indicated, and the use is non-commercial. See: http://creativecommons.org/licenses/by-nc/4.0/.

ORCID iDs

Tannaz Moin http://orcid.org/0000-0002-5035-6641

Jinnan Li http://orcid.org/0000-0002-8393-3118

\section{REFERENCES}

1 CDC. Prediabetes - Your Chance to Prevent Type 2. Diabetes 2019.
2 Tabák AG, Herder C, Rathmann W, et al. Prediabetes: a high-risk state for diabetes development. Lancet 2012;379:2279-90.

$3 \mathrm{Li} \mathrm{G}$, Zhang P, Wang J, et al. The long-term effect of lifestyle interventions to prevent diabetes in the China dA Qing diabetes prevention study: a 20-year follow-up study. Lancet 2008;371:1783-9.

4 Knowler WC, Barrett-Connor E, Fowler SE, et al. Reduction in the incidence of type 2 diabetes with lifestyle intervention or metformin. N Engl J Med 2002;346:393-403.

5 Gopalan A, Lorincz IS, Wirtalla C, et al. Awareness of prediabetes and engagement in diabetes risk-reducing behaviors. Am J Prev Med 2015;49:512-9.

6 CDC. Centers for disease control and prevention diabetes prevention and recognition program. CDC, 2011.

7 Geiss LS, James C, Gregg EW, et al. Diabetes risk reduction behaviors among U.S. adults with prediabetes. Am J Prev Med 2010;38:403-9.

8 Centers for Disease Control and Prevention (CDC). Self-reported prediabetes and risk-reduction activities--United States, 2006. MMWR Morb Mortal Wkly Rep 2008;57:1203-5.

9 American Diabetes A. Standards of medical care in diabetes-2015. Diabetes care 2015;38:S1-87.

10 Gregg EW, Ali MK, Moore BA, et al. The importance of natural experiments in diabetes prevention and control and the need for better health policy research. Prev Chronic Dis 2013;10:E14.

11 Ackermann RT, Kenrik Duru O, Albu JB, et al. Evaluating diabetes health policies using natural experiments: the natural experiments for translation in diabetes study. Am J Prev Med 2015;48:747-54.

12 Duru OK, Mangione CM, Chan C, et al. Evaluation of the diabetes health plan to improve diabetes care and prevention. Prev Chronic Dis 2013;10:E16.

13 Duru OK, Turk N, Ettner SL, et al. Adherence to metformin, statins, and ACE/ARBs within the diabetes health plan (DHP). J Gen Intern Med 2015;30:1645-50.

14 McDonald RJ, McDonald JS, Kallmes DF, et al. Behind the numbers: propensity score analysis-a primer for the diagnostic radiologist. Radiology 2013;269:640-5.

15 Heinze G, Jüni P. An overview of the objectives of and the approaches to propensity score analyses. Eur Heart $J$ 2011:32:1704-8.

16 Dehejia RH, Wahba S. Causal effects in Nonexperimental studies: Reevaluating the evaluation of training programs. J Am Stat Assoc 1999;94:1053-62.

17 Stuart EA. Matching methods for causal inference: a review and a look forward. Stat Sci 2010;25:1-21.

18 Allison P, Data M. In: Lewis-Beck MS, ED. Quantitative applications in the social science. Thousand Oaks, CA 2002.

19 Rubin DB. Multiple imputation after 18+ years. J Am Stat Assoc 1996;91:473-89.

20 White IR, Royston P, Wood AM. Multiple imputation using chained equations: issues and guidance for practice. Stat Med 2011;30:377-99.

21 Sonier J, Fried B, Au-Yeng C, et al. State-level trends in employersponsored health insurance Minneapolis. MN: University of Minnesota, 2013 